\title{
Pathophysiology of vascular dementia
}

\section{Francesco Iemolo*1,2,3,4, Giovanni Duro ${ }^{4}$, Claudia Rizzo5,6, Laura Castiglia5,6, Vladimir Hachinski ${ }^{1}$ and Calogero Caruso ${ }^{5,6}$}

\begin{abstract}
Address: ${ }^{1}$ Department of Clinical Neurological Sciences University of Western Ontario, Ontario, Canada, ${ }^{2}$ Robarts Research Institute Stroke Prevention \& Atherosclerosis Research Centre, London, England, UK, ${ }^{3}$ U.O. di Neurologia, Ospedale di Vittoria, ASL7-Ragusa and Clinica Neurologica Università di Catania, Catania, Italia, ${ }^{4}$ Istituto di Biomedicina ed Immunologia Molecolare-Consiglio Nazionale delle Ricerche (IBIMCNR), Palermo, Italy, ${ }^{5}$ U.O. di Immunoematologia e Medicina Trasfusionale, AOUP "Paolo Giaccone", Palermo, Italy and ${ }^{6}$ Dipartimento di Biopatologia e Metodologie Biomediche, Università di Palermo, Palermo, Italy

Email: Francesco Iemolo* - f.iemolo@tin.it; Giovanni Duro - duro@ibim.cnr.it; Claudia Rizzo - claudia.rizzo@unipa.it; Laura Castiglia - lcastiglia@unipa.it; Vladimir Hachinski - Vladimir.hachinski@lhsc.on.ca; Calogero Caruso - marcoc@unipa.it

* Corresponding author
\end{abstract}

Published: 6 November 2009

Immunity \& Ageing 2009, 6:13 doi:10.11 86/1742-4933-6-13
Received: 25 May 2009

Accepted: 6 November 2009

This article is available from: http://www.immunityageing.com/content/6/I/13

(c) 2009 lemolo et al; licensee BioMed Central Ltd.

This is an Open Access article distributed under the terms of the Creative Commons Attribution License (http://creativecommons.org/licenses/by/2.0), which permits unrestricted use, distribution, and reproduction in any medium, provided the original work is properly cited.

\begin{abstract}
The concept of Vascular Dementia $(\mathrm{VaD})$ has been recognized for over a century, but its definition and diagnostic criteria remain unclear.

Conventional definitions identify the patients too late, miss subjects with cognitive impairment short of dementia, and emphasize consequences rather than causes, the true bases for treatment and prevention. We should throw out current diagnostic categories and describe cognitive impairment clinically and according to commonly agreed instruments that document the demographic data in a standardized manner and undertake a systematic effort to identify the underlying aetiology in each case.

Increased effort should be targeted towards the concept of and criteria for Vascular Cognitive Impairment and Post-Stroke Dementia as well as for genetic factors involved, especially as these categories hold promise for early prevention and treatment.
\end{abstract}

\section{Background}

The concept of Vascular Dementia (VaD), has been recognized for over a century, but its definition and diagnostic criteria remain unclear and generate, much confusion and debate althoung several clinical criteria have been used for defining the $\mathrm{VaD}$

The term of VaD substantially means "disease with a cognitive impairment resulting from cerebrovascular disease and ischemic or hemorrhagic brain injury".
Dementia represents only a portion of the burden of cognitive dysfunction associated with cerebrovascular disease. In addition to patients who develop dementia, there are those who develop cognitive impairment that does not fulfill traditional criteria for dementia but that nonetheless has a significant impact on quality of life and ability to carry out activities of daily living. As a result, the older term "vascular dementia" is being replaced with a new one: "vascular cognitive impairment" (VCI). In addition, postmortem pathological studies indicate that $15 \%$ 
to $34 \%$ of dementia cases show significant vascular pathology, either alone or in combination with Alzheimer disease (AD) pathology [1].

In fact, dementia criteria are typically modelled on Alzheimer Disease (AD), wherein involvement of the mesial temporal lobe results in dense episodic memory impairment. [2,3]. Current research has led to the identification of a cognitive syndrome signalling a high risk of further cognitive decline, a group of patients similar to that of mild cognitive impairment as a risk state for AD [4]. The cognitive impairment attributable to cerebrovascular disease is a rapidly escalating public health problem. The heterogeneity of the population of patients with $\mathrm{VaD}$ diagnosed using current criteria has raised the need for updating the classification of subtypes

\section{History}

The concept of "dementia" originated early in the $16^{\text {th }}$ century., when for the first time Pratensis mentioned the "Dementia stroke correlate". in the "De cerebri morbis 1549" Subsequently Willis described the most important causes of dementia including ageing and vascular disease and the first accurate clinical observations of patients with vascular dementia In the early $19^{\text {th }}$ century Cooke described "intellectual deficits among the sequelae of apoplexy" The history of vascular dementia during $19^{\text {th }}$ and $20^{\text {th }}$ centuries has been recently reviewed [5].

Binswanger and Alzheimer, began a series of clinicopathological correlation studies attempting to isolate additional forms of dementia, describing four different form of vascular dementia (arteriosclerotic brain degeneration, perivascular gliosis of the brain cortex, dementia post-apoplexian and Binswanger's chronic progressive subcortical encephalitis) [6-16]. Pierre Marie described in 1901 the "état lacunaire" associated with a constant intellectual deficits. Dementia was separated from delirium and other psychiatric diseases at the end of the $19^{\text {th }}$ century, but its etiology remained un cleared [17].

Alzheimer and Binswanger had correctly concluded that "arteriosclerotic dementia" represented a large clinicopathological spectrum. However, "arteriosclerotic dementia" incorrectly became synonymous with senile dementia, and it was widely held that cortical atrophy in the elderly resulted from progressive decrease in cerebral perfusion leading to hypoxic neuronal death.

Little further progress was made for the next 70 years because of a combination of factors (Freud's work, Kraepelin's classification, syphilis as a common and obscuring cause of dementia). New suggestions and observations were made, but they did not thrive against this background. In 1946 a clear description of a multi- infarct dementia was given, recognizing the possible role of silent infarcts and explicating that the chronic ischemia wasn't he cause of vascular dementia, but the true mechanism was the infarction. This process later termed "multiinfarct dementia" [18]

Today, the importance of vascular lesions in Alzheimer's disease is being increasingly recognized: various data shows that more than $30 \%$ of AD exhibit cerebrovascular pathology [5].

A recent review define the $\mathrm{AD}$ as a vascular disorder: "...since the value of scientific evidence generally revolves around probability and chance, it is concluded that the data presented here pose a powerful argument in support of the proposal that AD should be classified as a vascular disorder. According to elementary statistics, the probability or chance that all these findings are due to an indirect pathological effect or to coincidental circumstances related to the disease process of AD seems highly unlikely. The collective data presented in this review strongly support the concept that sporadic AD is a vascular disorder." [19].

\section{Discussion \\ Vascular dementia (VAD) and vascular cognitive impairment (VCI): clinical criteria}

Cardinal elements implemented in the clinical criteria for $\mathrm{VaD}$ are the definition of the cognitive syndrome of dementia and the objective documentation of vascular lesions capable of causing dementia [20-24]. All the currently clinical criteria, are derived from expert opinion based on prevailing knowledge and pathogenetic hypothesis of dementia's causes [25].

The current clinical criteria for $\mathrm{VaD}$ recognize the multiplicity of lesions, but none of these clinical criteria provide guidelines for subtype of $\mathrm{VaD}$ [26]. Only the NINDSAIREN criteria mention the following subtype: cortical vascular dementia, Binswanger's disease and thalamic dementia [27]. Also the brain imaging requirements are not included, or are not complete, in all current clinical criteria.

The systematic heterogeneity of the population of patients with $\mathrm{VaD}$ diagnosed by using current criteria has raised the need for updating the classification of subtypes. The main subtype of $\mathrm{VaD}$ include: multi-infarct dementia or predominantly cortical $\mathrm{VaD}$, strategic infarct dementia and small vessel dementia or subcortical $\mathrm{VaD}$ even if only subcortical $\mathrm{VaD}$ is probably a more homogenous group [28-31]

The new criteria are based on homogeneity (in aetiologies, brain imaging and clinical syndrome), on predictability 
(phenomenology and clinical picture, clinical course and natural history, outcomes and treatment responses), on reproducibility (intra- and inter-rater reliability). Furthermore, they must be validated by prospective clinical pathological correlation [25,32].

The cornerstone of all criteria of dementia is memory impairment; this criterion works very well for $A D$, in which the mesial temporal lobes are affected early and prominently with consequent early memory loss, but strokes affecting cognition occur most commonly in the frontobasal systems that subserves judgement, planning and emotion, features seldom tested in cognitive screens.

At present, there is no generally accepted test battery for identifying or classifying patients with VCI. However, there are some basic principles that can be followed in developing such a battery. One of these is that large vessel cortical strokes and subcortical small vessel disease, tend to produce different kinds of deficits. The former typically present with region-specific syndromes such as aphasia, apraxia, and amnesia. The latter present with more subtle and temporally progressive deficits, often described as "executive" in nature. [4,33-37]. These include deficits in speed and so-called "strategic" processing (ie, attention, planning, and monitoring) in tasks such as memory tasks. Patients may perform normally on simple tasks but reveal deficits as tasks increase in complexity. It appears that the majority of VCI patients fall into the class with subcortical small vessel disease. $[21,38]$. Thus, it seems reasonable that neuropsychological testing for VCI would include tasks testing executive function. In addition, such tests may help to differentiate patients in which either vascular or $\mathrm{AD}$ pathologies predominate [1]

The extent of ischaemic disease on neuroimaging, that is both sufficient and necessary to cause cognitive impairment, Leukoaraiosis and atrophy as well as the issue of location [39]. To summarize the literature data, it's clear that there are insufficient data to propose firm cut-offs for the extent of Leukoaraiosis or for extent of infarction.

Anyway, enough scientific rationale already exists for undertaking systematic clinical trials in the prevention of cognitive impairment through the control of vascular risk factors and the use of statins, anti-inflammatory agents, ACE inhibitors, vitamins E and B12 [40].

\section{Epidemiology}

Epidemiologic studies of $\mathrm{VaD}$ have been hampered by the "lack of clear and universal diagnostic criteria, by the use of different strategies in detecting dementia cases of vascular origin, by the difficulties of developing an effective case-finding strategy, and by the complexity of using imaging or laboratory tests in large scale epidemiologic surveys" [41]. Despite these difficulties, the broad contours of VaD epidemiology are emerging slowly [42-44].

The data from current studies cannot be compared and reconciled easily. Diagnostic criteria for $\mathrm{VaD}$ have been a long standing source of disagreement and are perhaps the greatest barrier to reaching consensus on the epidemiology of this disease $[42,43,45]$. A first problem is the classification of patients with the so-called "mixed" dementia, in whom the aetiology appears to include both cerebrovascular and primary degenerative features. A second problem is the disagreement about criteria and evaluation of tools. A number of new sets of criteria have been introduced in the 1990s, including the ICD-10, the Chui et al., the Roman et al., and the DSM-IV criteria [46,47]. An additional problem with epidemiologic studies is the need to transfer published criteria into clinical instruments or procedures that can be implemented on a large scale. Brief scales to separate $\mathrm{VaD}$ from $\mathrm{AD}$ have been developed beginning with the Hachinski Ischemic Score (HIS) introduced in 1975. A number of modifications or transformations of this original scale have been proposed in the past 20 years [48]. Some of these scales require imaging tests, whereas others are purely clinical. A third problem is the use of imaging findings in the definition of $\mathrm{VaD}$ : in the incidence study of dementia in Rochester, the age-specific incidence rate of $\mathrm{VaD}$ by using more restrictive DSM-IV criteria (clinical stroke required) and less restrictive criteria (certain vascular imaging lesion sufficient) diverge beyond 70 years of age, and are more than doubled with the restrictive criteria beyond 85 years of age [49]. A fourth problem is to define the range of severity of $\mathrm{VaD}$ to be detected in the study: severity may vary from a mild cognitive impairment to terminal stages of deterioration.

If the prevalence of $\mathrm{VaD}$ is greater among women than men of a certain age, it remains uncertain whether women have a higher incidence of $\mathrm{VaD}$ or whether the incidence is equal to men, but survival after onset of $\mathrm{VaD}$ is better in women [41].

Today new prevalence studies are available) and the breadth of variation for $\mathrm{VaD}$ prevalence is now even wider. It remains unclear whether the differences between different countries reflect disagreement over diagnostic criteria for $\mathrm{VaD}$ or other methodological differences. For studies investigating the incidence of $\mathrm{VaD}$ in different countries the data are similarly disparate $[50,34]$.

The data available to answer the question if the prevalence or the incidence of $\mathrm{VaD}$ is increasing or decreasing over time are very few. Because the data from current studies cannot be easy reconciled, it remains very difficult to draw conclusions about the epidemiology of $\mathrm{VaD}$. Our progress 
would benefit greatly from the development of a new set of diagnostic criteria sensitive and specific, easy to apply in the field setting and internationally accepted. It appears, however, that the prevalence of $\mathrm{VaD}$ tends to be higher in men than in women, and that it increases with age; moreover there seems to have been a decline in both prevalence and incidence of $\mathrm{VaD}$ between the 1950s and 1970 s [41]. The prevalence of $\mathrm{VaD}$ ranged typically between $3 \%$ and $6 \%$; but the variation described ranged between $0 \%$ to $20 \%$. There are relatively few data regarding incidence in the general population. The incidence of cognitive impairment sufficient to adversely affect outcome but not meeting current criteria for vascular dementia is as high as $35.2 \%$ compared to $3.8 \%$ with a similar degree of impairment in stroke-free controls $[18,35,42]$.

\section{Pathophysiology}

Epidemiological studies have explored widely the potential risk factors or protective factors for different dementing disorders [36,51]. Many studies have focused on $\mathrm{AD}$ and more recently, on all types of dementia as a syndrome. Aetiological studies about VaD have been hampered by methodological issues and - the search for risk factors of $\mathrm{VaD}$ may potentially be more amenable to prevention than $\mathrm{AD}$ [52].

\section{Some common determinants between $\mathrm{AD}$ and $\mathrm{VaD}$ are:}

- risk factors involved in cerebrovascular disease (age, sex, some atherogenic disorders or vascular risk factors, genetic factors and inflammation). Other potential risk factors like occupational exposure to pesticide, psychological stress or life events, dietary fat intake, family history of stroke, etc.);

- potential protective factors (high educational attainment, eating fish or shellfish, physical exercise, use of supplementary antioxidants like Vitamins $\mathrm{E}$ and $\mathrm{C}$, use of Vitamin B12, Mediterranean diet, etc.) $[36,50,53]$.

Vascular cognitive impairment is not a regular pathogenetic entity. Multiple small thromboembolic strokes or strokes in strategic locations such as the thalamus, frontal lobe or temporal lobes may cause cognitive impairment and frequently occur without classical stroke-like symptoms. Nonetheless, in $\mathrm{VaD}$, the majority of patients instead present widespread microangiopathy-related cerebral damage, which is often clinically silent or is accompanied by unspecific neurological signs.

Several mechanisms may explain why patients affected by stroke are prone to develop dementia $[20,37,54,55]$ :

- post-stroke dementia may be the direct consequence of vascular lesions in the brain
- post-stroke dementia could be the result of pre-existing neuropathological effects AD's related

- recurrent stroke that is cause by vessel damages and by white matter lesions that may lead to cognitive decline and contribute to post-stroke dementia;

One of the mechanism involved in ischemic $\mathrm{VaD}$ is under the control of large vessels disease (atherosclerosis, and other arteriopathies), however, impaired cerebral flow in the absence of infarct as consequence of arterial stenosis has been documented, although its clinical consequences remain to be fully investigated. It is also unclear whether and to what degree large vessel disease contributes to the white matter pathology and lacunes associated with the subcortical type of $\mathrm{VaD}$. Statistical association suggests it may have additive effects to small vessel pathology. $[56,57]$

Moreover, the alterations of small vessels play a role in causing damage to the cerebral tissue and are potentially responsible for the subsequent development of cognitive alterations. Small vessel lesions are considered related to the deep lacunar infarcts and white matter changes typically observed in subcortical forms of vascular cognitive impairment.

The most common types of diseases affecting cerebral microvessels are: arteriosclerosis, lipohyalinosis, cerebral amyloid angiopathy, basal ganglia calcification, CADASIL (Cerebral Autosomal Dominant Arteriopathy with Subcortical Infarcts and Leucoencephalopathy), other uncommon intracerebral vasculopathies.

The small vessel alterations could also lead to damage affecting the blood-brain barrier and chronic leakage of fluid and macromolecules in the white matter, even if the neuroimaging methods do not detect diffuse alterations of the blood-brain barrier in vivo [58].

Another mechanism influencing small vessel alterations could be incomplete ischemia and selective tissue necrosis (i.e. incomplete infarction) causing a selective neuronal necrosis with sparing of glial cells and microvessels [5962].

Recently, it has been suggested a new variety of lacunar infarction, (type Ib), characterized by small areas of perivascular rarefaction and selective neuronal loss, followed in the more advanced stages by a varying amounts of depleted neurons and oligodendrocytes, astroglial response and minor central cavitation. Furthermore, embolic occlusion of small penetrating artery followed by spontaneous lyses of the thrombus could be responsible for these lacunes [63-65]. 
The concept of Leukoaraiosis, suggested by Hachinski, was introduced to describe morphological abnormalities of the white matter on imaging [66].

The pathogenesis of white matter changes (WMC) is not well established and a number of possible mechanisms have been hypothesized, all mechanisms are reconducible to a form of cerebrovascular disease. It has been proposed that the diffuse changes of the white matter should be considered a form of incomplete infarction. [67-76]

The understanding of the pathobiology of $\mathrm{AD}$ and $\mathrm{VaD}$ recived an impulse by the discovery of genes that produce monogenic forms of the illness or contribute to polygenic forms; in particular, the identification of genes contributing to VCI would no doubt provide insight into the cellular and molecular basis of VCI.

Genetic factors play an important role in the aetiology of $\mathrm{VaD}$, in particular, it's seems to be more important in large-vessel stroke and small vessel stroke than in cryptogenic stroke, and there is no epidemiological evidence for a genetic component in cardioembolic stroke.

The genes underlying $\mathrm{VaD}$ must be of 2 nonmutually exclusive classes: (1) genes that predispose individuals to cerebrovascular disease, and (2) genes that determine tissue responses to cerebrovascular disease (eg, genes conveying ischemic tolerance or susceptibility, or the ability to recover from ischemic insult). With regard to the first class of genes, some progress has been made in the past few years in identifying genes that confer susceptibility to hypertension and stroke [77]. In addition, several monogenic forms of cerebrovascular disease have been identified. The two best studied of these are cerebral autosomal dominant arteriopathy with subcortical infarcts and leucoencephalopathy (CADASIL: a subcortical small vessel disease accompanied by lacunar strokes, migraine, and dementia) and hereditary cerebral hemorrhage with amyloidosis-Dutch type (HCHWA-D) [1].

The CADASIL condition is a heritable small-vessel disease caused by mutations in NOTCH3 gene which is normally expressed in vascular smooth muscle cells and pericytes (including those of the cerebral vasculature) and that encodes a cell-surface receptor, which has a role in arterial development and is expressed on vascular smooth-muscle cells. appears to be involved in directing smooth muscle cell proliferation and differentiation. The NOTCH3 receptor is a heterodimer composed of a large extracellular fragment and a smaller transmembrane intracellular fragment. About $95 \%$ of patients have missense mutations that cluster in exons 3- and consist in change of cysteine residues amount, but the pathogenic meccanism is still unknown $[78,79]$.
Whit regard to HCHWA-D (a syndrome of primarily hemorrhagic strokes and dementia), it is caused by a mutation in the gene for amyloid precursor protein (APP) that causes abnormal deposition of amyloid in the walls of leptomeningeal arteries and cortical arterioles (a mpathological condition known as cerebral amyloid angiopathy [CAA]). Mouse models have been developed for CADASIL and HCHWA-D and have contributed critical insights into the cell biology of the pathogenic processes underlying them. [80]

In contrast, little attention has been paid to the second class of genes: those that render the brain more or less susceptible to injury in response to cerebrovascular disease. Evidence for the existence of such response genes is that patients with apparently similar loads of vascular pathology (with regard to lesion type, number, and location) may range from no cognitive impairment to severely cognitively impaired. The association studies using the candidate gene approach, has identified a number of genetic variants possibly involved in risk factor development and, on the other hand, suggests that the risk of stroke has a substantial genetic component. Nonetheless, the genes underlying this risk in the general population remain undetermined. Genetic factors can act at several levels. They can contribute to conventional risk factors such as hypertension, diabetes, or homocysteine concentrations, which have a known genetic components. They might further interact with environmental factors or contribute directly to an intermediate phenotype $[78,81]$

It is also possible that some genetic factors contribute, by interaction with conventional risk factors, to the development of subcortical injury of vascular origin in non familiar cases.

Most single-gene disorders are associated with specific stroke subtypes, especially in young stroke patients without known risk factors. Table 1; ref. [79,82-87].

In this group of diseases we take in consideration only Fabry's disease for its special association with stroke. The Fabry's disease is an X-linked systemic disorder caused by deficiency of the lysosomal enzyme $\alpha$-galactosidase A, that results in progressive accumulation of glycosphingolipids in the myocardium, renal epithelium, skin, eye, and vasculature. The symptoms are acroparesthesia, angiokeratoma, hypoidrosis, which start during the childhood or adolescence and are present in the majority of the affected individuals and many young patients are affect by cryptogenetic stroke. The disease occurs either in large-artery either in small-vessel disease, with a preference for posterior circulation. Small-vessel disease in Fabry's disease is associated with white-matter changes and evidence suggests that the extent of such lesions is influenced by gene 
Table I: Single-gene disorders associated with ischaemic stroke (for reference see the text)

\begin{tabular}{llcl}
\hline \multicolumn{1}{c}{ Gene } & \multicolumn{1}{c}{ Disease } & $\begin{array}{c}\text { Mode of } \\
\text { inheritance }\end{array}$ & \multicolumn{1}{c}{ Stroke mechanism } \\
GAL & Fabry's disease & X-linked & Large-artery disease and small-vessel disease \\
NOTCH3 & CADASIL & $A D$ & Small-vassel disease \\
HBB & Sickle-cell disease & $A R$ & Large-artery disease, small-vessel disease, haemodynamic insufficiency \\
CBS and others & Homocystinuria & $A R$ & Large-artery disease, cardioembolism, small-vessel disease, arterial dissection \\
mENA & MELAS & Maternal & Complex (microvascular and neuronal factors) \\
FBNI & Marfan syndrome & $A D$ & Cardioembolism and arterial dissection \\
COL3AI & Ehlers-Danlos syndrome type IV & $A D$ & Arterial dissection \\
ABCC6 & Pseudoxanthoma elasticum & $A R$ & Large-artery disease and small-vessel disease \\
\hline
\end{tabular}

$\mathrm{AD}=$ autosomal dominant. $\mathrm{AR}=$ autosomal recessive. $\mathrm{HBB}=$ haemoglobin beta. $\mathrm{CADASIL}=$ cerebral autosomal dominant arteriopathy with subcortical infarcts and leucoencephalopathy. MELAS = mitochondrial myopathy, encephalopathy, lactacidosis, and stroke. mtDNA = mitochondrial DNA.

For references, see text

polymorphisms as interleukin 6 , endothelial nitric oxide synthase, factor $\mathrm{V}$, and protein $\mathrm{Z}[78,82]$. These findings are suggestive but need further confirmation (Duro's data not published).

The genetic contribution to common multifactorial stroke seems to be polygenic: there are many alleles with small effect, due to their wide distribution, however, on a population basis the impact on stroke is large. Several genes and polymorphisms were selected for a significant association with ischaemic stroke: in particular polymorphisms in the genes encoding MTHFR (enzyme in homocysteine metabolism), ACE (enzyme in renin-angiotensin-aldosterone system), Factor V Leiden, prothrombin and PAI 1 (Haemostatic system) [78]

Recently, studies for the analyses of ischemic stroke assessed two unsuspected common SNPs on chromosome 12p13 (rs11833579 and rs12425791), consistently associated with total ischemic, and atherothrombotic stroke in caucasic population although there is association with ischemic and atherothrombotic strokes (as compared with total stroke), but no association with non ischemic stroke. The SNPs are on the gene NINJ2 that encodes an adhesion molecule expressed in glia cells and shows increased expression after nerve injury Some mutations are associated with a slightly more aggressive phenotype. [81].

One class of genes that must influence tissue responses to cerebrovascular disease are the AD genes. There is an additive or synergistic interaction between $\mathrm{AD}$ and cerebrovascular pathologies, such that individuals with both of these pathologies show greater cognitive impairment than those exhibiting either pathology alone. In addition, at least three sets of genes in the $\mathrm{AD}$ pathway, the presenilins, APP, and apolipoprotein E (apoE), are known to interact with the VCI disease pathway.
The presenilins, mutations of which cause $\mathrm{AD}$, have been shown to interact directly with Notch proteins, including Notch 3 (mutations of which cause CADASIL).

Mutations in the APP gene can lead either to AD or to hemorrhagic stroke and dementia (as in HCHWA-D) depending on the site of the mutation and the subsequent cellular site of amyloid accumulation.

Variants of the apoE gene appear to affect not only susceptibility to cerebrovascular disease but also recuperative responses to it (see below). Thus, there appear to be links in the biochemical pathways underlying $\mathrm{VCI}$ and $\mathrm{AD}$ pathologies, which could be responsible for the observed interactive effects of these pathologies on cognitive function.

Genes that influence brain responses to cerebrovascular disease do not appear to be limited to those within $\mathrm{AD}$ pathway. First, it has been shown that VCI can occur in the complete absence of AD pathology in sporadic VCI and in hereditary forms. In addition, the cognitive sequelae of pathogenic processes associated with VCI are different from those seen in "pure" $\mathrm{AD}$, in that executive function appears more strongly affected in VCI than is memory. Consistent with these observations, different brain regions seem differentially affected in VCI and AD, with prefrontal circuits being more affected in VCI and the hippocampus in $\mathrm{AD}$.

An important aspect of VaD's (AD's particular) pathophysiology, is the role of inflammation: the incidence is influenced by the gene polymorphisms of the inflammatory mediators. Among the most widely investigated genes are those involved in inflammation (interleukin 1, interleukin 6, TNFo, toll-like receptor 4, P-selectin and Eselectin, C-reactive protein), lipid metabolism (apolipoprotein $\mathrm{E}$, paraoxonase, epoxide hydrolase), nitric oxide 
release, and extracellular matrix (matrix metalloproteinases) [88,89].

Infact, in recent years, an increasing set of evidence has stress the role of inflammation in the brain, particularly in the microglia-rich amyloid deposits, where the microglias tend to release a wide variety of proinflammatory mediators including cytokines (IL $1 \beta$, IL $6, \operatorname{TNF} \alpha$, acute phase proteins) complement components, various free radicals and nitric oxide (NO), all of which potentially contribute to further neuronal dysfunction and eventually result in cellular death. In addition, apolipoprotein E (ApoE) is strongly associated with AD in terms of cognitive decline and disease onset: ApoE, especially the $\varepsilon 4$ allele, has been observed promoting an inflammatory reaction[14]. The AD's pathomechanism is related to the accumulation of toxic amyloid- $\beta(\mathrm{A} \beta)$, which precipitate along the vessel walls and in brain parenchymal plaques, as well as the formation of neurofibrillary tangles (NFTs); the development of cognitive impairment in $\mathrm{VaD}$ may be related to a number of different pathological processes including multiple infarctions resulting from occlusion of major brain vessels or their branches and lypohyalinosis. The latter is a degeneration of small arterial vessel walls supplying the subcortical white matter, thalamus, and basal ganglia, or cerebral amyloid angiopathy (CAA is the accumulation of amyloid protein in the walls of cerebral blood vessels): less commonly, vascular dementia is related to deposition of $A \beta$ in brain vessels. CAA can be either sporadic or familial. The progressive cognitive impairment in CAA results from multiple brain hemorrhages and/or ischemia related to narrowing of vessel lumen $[88,90]$

\section{Conclusion}

We should throw out current diagnostic categories and describe cognitive impairment clinically and according to commonly agreed instruments that document the demographic data in a standardized manner and undertake a systematic effort to identify the underlying aetiology in each case (imaging and DNA should be obtained whenever possible.

However, further empirical research and international debate is needed to define the syndrome and stages of vascular subcortical cognitive impairment, validate the brain imaging criteria for subcortical Vascular Dementia by clinical-pathological correlation, as well as the natural history and outcomes of the syndrome.

Increased effort should be targeted towards the concept of and criteria for Vascular Cognitive Impairment and PostStroke Dementia as well as for genetic factors involved, especially as these categories hold promise for early prevention and treatment.

\section{Competing interests}

The authors declare that they have no competing interests.

\section{Authors' contributions}

All authors drafted, read and approved the final manuscript.

\section{Acknowledgements}

Laura Castiglia is a PhD student at Pathobiology Course of Palermo University (directed by Calogero Caruso) and this paper is in partial fulfillment of the requirement for her PhD.

\section{References}

I. Leblanc GG, Meschia JF, Stuss DT, Hachinski V: Genetics of Vascular Cognitive Impairment The Opportunity and the Challenges. Stroke 2006, 37:248-255.

2. Rockwood K, Wentzel C, Hachinski V, Hogan DB, MacKnight C, McDowell I: Prevalence and outcomes of vascular cognitive impairment. Neurology 2000, 54:447-5I.

3. Petersen RC: Aging, mild cognitive impairment, and Alzheimer's disease. Neurol Clin 2000, 18:789-806.

4. Candore G, Balistreri CR, Grimaldi MP, Vasto S, Listì F, Chiappelli M, Licastro F, Lio D, Caruso C: Age-related inflammatory diseases: role of genetics and gender in the pathophysiology of Alzheimer's disease. Ann N Y Acad Sci 2006, 1089:472-86.

5. Roman GC: A historical review of the concept of vascular dementia: lessons from the past for the future. Alzheimer Dis Assoc Disord 1999, 13:S4-8.

6. Caruso C, Franceschi C, Licastro F: Genetics of neurodegenerative disorders. N Engl J Med 2003, 349: 193-4.

7. Roman GC: Historical aspects: from Alzheimer to Binswanger. New York: Thieme; 1992:83-85.

8. Beach TG: The history of Alzheimer's disease: three debates. Hist Med Allied Sci 1987, 42:327-49.

9. Berrios GE: Alzheimer's disease: a conceptual history. Int J Geriat Psych 1990, 5:355-65.

10. Berrios GE, Freeman HL: Alzheimer and the dementias. London. Royal Society of Medicine Ser 1991.

II. Bick KL: The early story of Alzheimer disease. New York: Raven Press; 1994: I-8.

12. Weber MM: Aloys Alzheimer, a coworker of Emil Kraepelin. J Psychiatr Res 1997, 31:635-43.

13. Racchi M, Uberti D, Govoni S, Memo M, Lanni C, Vasto S, Candore G, Caruso C, Romeo L, Scapagnini G: Alzheimer's disease: new diagnostic and therapeutic tools. Immun Ageing 2008, 13:5-7.

14. Vasto S, Candore G, Listì F, Balistreri CR, Colonna-Romano G, Malavolta M, Lio D, Nuzzo D, Mocchegiani E, Di Bona D: Inflammation, genes and zinc in Alzheimer's disease. Brain Res Rev 2008, 58:96-105.

15. Lio D, Scola L, Romano GC, Candore G, Caruso C: Immunological and immunogenetic markers in sporadic Alzheimer's disease. Aging Clin Exp Res 2006, 18:163-6.

16. Mast $\mathrm{H}$, Tatemichi TK, Mohr JP: Chronic brain ischemia: the contributions of Otto Binswanger and Alois. J Neurol Sci 1995, 132:4-10.

17. Dening TR, Berrios GE: The vascular dementia. Royal Society of Medicine Service Ltd; 1991:69-76.

18. Bowler J, Hachinski V: Vascular dementia. Cerebrovascular Disease: pathophysiology, diagnosis, and management. Science Ltd 1998: I I26-44.

19. De la Torre JC: Alzheimer disease as a vascular disorder: nosological evidence. Stroke 2002, 33: I I52-62.

20. Pohjasvaara T, Mantyla R, Salonen O, Aronen HJ, Ylikoski R, Hietanen $M$, Kaste $M$, Erkinjuntti $T$ : How complex interactions of ischemic brain infarcts, white matter lesions. Arch Neurol 2000, 57:1295-00.

21. Roman GC, Tatemichi TK, Erkinjuntti T, Cummings JL, Masdeu JC, Garcia JH, Amaducci L, Orgogozo JM, Brun A, Hofman A: Vascular dementia: diagnostic criteria for research studies. Neurology 1993, 43:250-60. 
22. Erkinjuntti T, Ostbye T, Steenhuis R, Hachinski V: The effect of different diagnostic criteria on the prevalence of dementia. $N$ Engl J Med 1997, 337:1667-74.

23. Pohjasvaara T, Erkinjuntti $T$, Vataja $R$, Kaste $M$ : Dementia three months after stroke. Baseline frequency and effect of different definitions of dementia in the Helsinki Stroke Aging Memory Study (SAM) cohort. Stroke 1997, 28:785-92.

24. McKhann G, Drachman D, Folstein M, Katzman R, Price D, Stadlan EM: Clinical diagnosis of Alzheimer's disease: report of the NINCDS-ADRDA Work Group under the auspices fo Department of Health and Human Service Task Force on Alzheimer's disease. Neurology 1984, 34:939-44.

25. Wetterling T, Kanitz RD, Borgis KJ: The ICD-I 0 criteria for vascular dementia. Dementia 1994, 5: 185-88.

26. Erkinjuntti T, Roman GC, Chui H: Diagnostic criteria. Vascular Cognitive Impairment. Martin Dunitz 2002:43-57.

27. World Health Organisation: Classification of Mental and Behavioural Disordes: diagnostic criteria for research. Geneve 1993.

28. Rockwood K, Bowler J, Erkinjuntti T, Hachinski V, Wallin A: Subtypes of vascular dementia. Alzheimer Dis Assoc Disord 1999, 13:S59-65

29. Brun A: Pathology and pathophysiology of cerebrovascular dementia: pure subgroups of obstructive and hypoperfusive etiology. Dementia 1994, 5:145-47.

30. Cummings JL: Vascular subcortical dementias: clinical aspects. Dementia 1994, 5:177-80.

31. Wallin A, Blennow K: The clinical diagnosis of vascular dementia. Dementia 1994, 5: 181-184.

32. Erkinjuntti T, Inzitari D, Pantoni L, Wallin A, Scheltens P, Rockwood $K$, Desmond DW: Limitations of clinical criteria for the diagnosis of vascular dementia in clinical trials: is a focus on subcortical vascular dementia a solution? Ann N Y Acad Sci 2000 , 903:262-72

33. Brayne C, Gill C, Huppert FA, Barkley C, Gehlhaar E, Girling DM, O Connor DW, Paykel ES: Incidence of clinically diagnosed subtypes of dementia in an elderly. Br J Psychiatry 1995, 167:255-62

34. Liu CK, Lai CL, Tai CT, Lin RT, Yen YY, Howng SL: Incidence and subtypes of dementia in southern Taiwan. Neurology 1998, 50: $1572-79$

35. Tatemichi TK, Desmond DW, Stern Y, Paik M, Sano M, Bagiella E Cognitive impairment after stroke: frequency, patterns, and relationship. I Neurol Neurosurg Psychiatry 1994, 57:202-07.

36. Fratiglioni L: Epidemiology of Alzheimer's disease and current possibilities. Acta Neurol Scand Suppl 1996, 165:33-40.

37. Pohiasvaara T, Erkinjuntti T, Ylikoski R, Hietanen M, Vataja R, Kaste $\mathrm{M}$ : Clinical determinants of poststroke dementia. Stroke 1998 , 29:75-8I.

38. Pepin M, Schwarze U, Superti-Furga A, Byers PH: Clinical and genetic features of Ehlers-Danlos syndrome type IV, the vascular type. N Engl J Med 2000, 342:673-80

39. Erkinjuntti T, Inzitari D, Pantoni L, Wallin A, Scheltens P, Rockwood K, Roman GC, Desmond DW: Research criteria for subcortica vascular dementia in clinical trials. I Neural Transm Suppl 2000, 59:23-30.

40. Hachinski VC, Bowler JV: Vascular dementia. Neurology 1993, 43:2159-60.

4I. Rocca WA, Kokmen E: Frequency and distribution of vascular dementia. Alzheimer Dis Assoc Disord 1999, I3:S9-14.

42. Rocca WA, Hofman A, Brayne C, Breteler MM, Clarke M, Copeland JR, Dartigues JF, Engedal K, Hagnell O, Heeren TJ: The prevalence of vascular dementia in Europe: facts and fragments from. Ann Neurol 1991, 30:817-24.

43. Hebert R, Brayne C: Epidemiology of vascular dementia. Neuroepidemiology 1995, I 4:240-57.

44. Jorm AF, Jolley $\mathrm{D}$ : The incidence of dementia: a meta-analysis. Neurology 1998, 5 I:728-33.

45. Wetterling T, Kanitz RD, Borgis KJ: Comparison of different diagnostic criteria for vascular dementia ADDTC. Stroke 1996, 27:30-6.

46. World Health Organisation: International Statistical Classification of Diseases and Related Health Problems. WHO; 1992.

47. Ott A, Breteler MM, van Harskamp F, Claus J], Cammen TJ van der, Grobbee DE, Hofmann A: Prevalence of Alzheimer's disease and vascular dementia: association with education. The Rotterdam study. BM] 1995, 31 0:970-73.
48. Tatemichi TK, Paik M, Bagiella E, Desmond DW, Stern Y, Sano M, Hauser WA, Mayeux R: Risk of dementia after stroke in a hospitalized cohort: results of a longitudinal study. Neurology |994, 44:|885-9|.

49. Knopman DS, Rocca WA, Cha RH, Edland SD, Kokmen E: Survival study of vascular dementia in Rochester, Minnesota. Arch Neurol 2003, 60:85-90.

50. Fratiglioni L, Grut M, Forsell Y, Viitanen M, Grafstrom M, Holmen K, Ericsson K, Bäckman L, Ahlbom A, Winblad B: Prevalence of Alzheimer's disease and other dementias in an elderly urban population: relationship with age, sex, and education. Neurology |99|, 41: I886-92

51. Skoog I, Nilsson L, Palmertz B, Andreasson LA, Svanborg A: A population-based study of dementia in 85-year-olds. N Engl j Med 1993, 328: 153-58.

52. Hachinski V: Preventable senility: a call for action against the vascular dementias. Lancet 1992, 340:645-48.

53. Fratiglioni L, Viitanen $M$, von Strauss $E$, Tontodonati $V$, Herlitz A Winblad B: Very old women at highest risk of dementia and Alzheimer's disease. Neurology 1997, 48: |32-38.

54. Pasquier F, Leys D: Why are stroke patients prone to develop dementia? J Neurol 1997, 244:135-42.

55. Schmidt H, Schmidt R: Genetic factors. In Vascular Cognitive Impairment Edited by: Erkinjuntti T, Gauthier S. London: Martin Dunitz Ltd; 2002:85-100.

56. Vinters HV, Ellis WG, Zarow C, Zaias BW, Jagust WJ, Mack WJ, Chui HC: Neuropathologic substrates of ischemic vascular dementia. J Neuropathol Exp Neurol 2000, 59:93 I-45.

57. Munoz DG, Leys D: Large vessel pathology. In Vascular Cognitive Impairment Edited by: Erkinjuntti T, Gauthier S. London: Martin Dunitz Ltd; 2002:101-14.

58. Bronge L, Wahlund LO: White matter lesions in dementia: an MRI study on blood-brain barrier. Dement Geriatr Cogn Disord 2000, I I:263-67.

59. Markus HS, Barley J, Lunt R, Bland JM, Jeffery S, Carter ND, Brown $\mathrm{MM}$ : Angiotensin-converting enzyme gene deletion polymorphism. A new risk. Stroke 1995, 26:1329-33.

60. Pantoni L, Lammie GA: Cerebral small vessel disease: pathological and pathophysiological aspects in relation to vascular cognitive impairment. In Vascular Cognitive Impairment Edited by: Erkinjuntti T, Gauthier S. London: Martin Dunitz; 2002:I I5-33.

61. Garcia JH, Lassen NA, Weiller C, Sperling B, Nakagawara J: Ischemic stroke and incomplete infarction. Stroke 1996, 27:76I-65.

62. Lassen NA: Incomplete cerebral infarction--focal incomplete ischemic tissue necrosis. Stroke 1982, 13:522-23.

63. Lammie GA, Brannan F, Wardlaw JM: Incomplete lacunar infarction (Type Ib lacunes). Acta Neuropathol (Berl) I998, 96: I63-7I.

64. Poirier J, Derouesne C: Cerebral lacunae. A proposed new classification. Clin Neuropathol 1984, 3:266

65. Pantoni L: Incomplete lacunar infarction: an alternative hypothesis. Acta Neuropathol (Berl) 1999, 97:322.

66. Hachinski VC, Potter P, Merskey H: Leuko-araiosis. Arch Neurol 1987, 44:21-3.

67. Pantoni L, Garcia JH: Pathogenesis of leukoaraiosis: a review. Stroke 1997, 28:652-59.

68. Longstreth WT Jr, Manolio TA, Arnold A, Burke GL, Bryan N, Jungreis CA, Enright PL, O'Leary D, Fried L: Clinical correlates of white matter findings on cranial magnetic resonance. Stroke 1996, 27:1274-82

69. Liao D, Cooper L, Cai J, Toole JF, Bryan NR, Hutchinson RG, Tyroler $H A$ : Presence and severity of cerebral white matter lesions and hypertension. Stroke 1996, 27:2262-70.

70. Liao D, Cooper L, Cai J, Toole J, Bryan N, Burke G, Shahar E, Nieto J, Mosley T, Heiss G: The prevalence and severity of white matter lesions, their relationship with age, ethnicity, gender, and cardiovascular disease risk factors: the ARIC Study. Neuroepidemiology 1997, 16:149-62.

7I. Inzitari D, Di Carlo A, Mascalchi M, Pracucci G, Amaducci L: The cardiovascular outcome of patients with motor impairment and extensive. Arch Neurol 1995, 52:687-91.

72. Inzitari D, Cadelo M, Marranci ML, Pracucci G, Pantoni L: Vascular deaths in elderly neurological patients with leukoaraiosis. Neurol Neurosurg Psychiatry 1997, 62:177-81.

73. Yao H, Sadoshima S, Ibayashi S, Kuwabara Y, Ichiya Y, Fujishima M: Leukoaraiosis and dementia in hypertensive patients. Stroke 1992, 23:1673-77. 
74. Pantoni L, Garcia JH, Gutierrez JA: Cerebral white matter is highly vulnerable to ischemia. Stroke 1996, 27:164|-46.

75. Pantoni L: Experimental approaches to white matter disease. Dement Geriatr Cogn Disord 1998, 9:20-4.

76. Petito CK, Olarte JP, Roberts B, Nowak TS, Pulsinelli WA: Selective glial vulnerability following transient global ischemia in rat. J Neuropathol Exp Neurol 1998, 57:23I-38.

77. Casas JP, Hingorani AD, Bautista LE, Sharma P: Meta-analysis of genetic studies in ischemic stroke: thirty-two genes involving approximately 18000 cases and 58000 controls. Arch Neurol 2004, 61: 1652-1661.

78. Dichgans M: Genetics of ischaemic stroke. Lancet Neurol 2007, 6:|49-6|.

79. Ungaro C, Mazzei R, Conforti FL, Sprovieri T, Servillo P, Liguori M, Citrigno L, Gabriele AL, Magariello A, Patitucci A: Cadasil: Extended Polymorphisms and Mutational Analysis of the NOTCH3 Gene. J Neuroscience Research 2009, 87: I | 62-67.

80. Herzig MC, Winkler DT, Burgermeister P, Pfeifer M, Kohler E, Schmidt SD, Danner S, Abramowski D, Sturchler-Pierrat C, Burki K: Abeta is targeted to the vasculature in a mouse model of hereditary cerebral hemorrhage with amyloidosis. Nat Neurosci 2004, 7:954-960.

81. Ikram MA, Seshadri S, Bis JC, Fornage M, DeStefano AL, Aulchenko YS, Debette S, Lumley T, Folsom AR, Herik EG van den: Genomewide Association Studies of Stroke. N Engl Med 2009, 360: $1718-28$.

82. Rolfs A, Böttcher T, Zschiesche M, Morris P, Winchester B, Bauer P, Walter U, Mix E, Löhr M, Harzer K: Prevalence of Fabry disease in patients with cryptogenic stroke: a prospective study. Lancet 2005, 366: 1794-96.

83. Hoppe C, Klitz W, Cheng S, Apple R, Steiner L, Robles L, Girard T, Vichinsky E, Styles L, CSSCD Investigators: Gene interactions and stroke risk in children with sickle cell anemia. Blood 2004, 103:2391-96.

84. Kelly PJ, Furie KL, Kistler JP, Barron M, Picard EH, Mandell R, Shih VE: Stroke in young patients with hyperhomocysteinemia due to cystathionine beta-synthase defi ciency. Neurology 2003 , 60:275-79.

85. Martinez-Fernandez E, Gil-Peralta A, Garcia-Lozano R, Chinchón I, Aguilera I, Fernández-López O, Arenas J, Campos Y, Bautista J: Mitochondrial disease and stroke. Stroke 200I, 32:2507-10.

86. Judge DP, Dietz HC: Marfan's syndrome. Lancet 2005, 366: 1965-76.

87. Berg JS Van den, Hennekam RC, Cruysberg JR, Steijlen PM, Swart J, Tijmes N, Limburg M: Prevalence of symptomatic intracranial aneurysm and ischaemic stroke in pseudoxanthoma elasticum. Cerebrovasc Dis 2000, 10:315-19.

88. Sadowski M, Pankiewicz J, Scholtzova H, Li YS, Quartermain D, Duff $\mathrm{K}$, Wisniewski T: Links between the pathology of Alzheimer's disease and Vascular Dementia. Neurochemical Research 2004, 29:1257-66.

89. Wan Y, Wang G, Chen SD: Genetic predisposition to inflammation: a new risk factor of Alzheimer's disease. Neurosci Bull 2008, 24:3|4-22.

90. Nuzzo D, Mocchegiani E, Di Bona D, Caruso C: Inflammation, genes and zinc inAlzheimer's disease. Brain Res Rev 2008, 58:96-105.
Publish with Bio Med Central and every scientist can read your work free of charge

"BioMed Central will be the most significant development for disseminating the results of biomedical research in our lifetime. "

Sir Paul Nurse, Cancer Research UK

Your research papers will be:

- available free of charge to the entire biomedical community

- peer reviewed and published immediately upon acceptance

- cited in PubMed and archived on PubMed Central

- yours - you keep the copyright
BioMedcentral 